\title{
Orientação Profissional em Contexto Coletivo: Uma experiência em Pré- Vestibular Popular
}

Vocational guidance: An experience at a popular preparation course for the university entrance examination

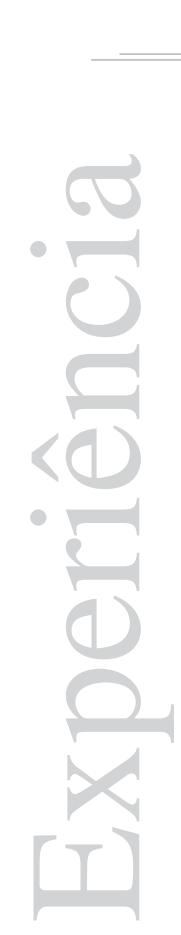

Dulce Helena

Penna Soares, Edite Krawulski, Maria Sara de Lima Dias \& Geruza T. D’Avila

Universidade Federal de Santa Catarina 
Resumo: Este artigo relata uma atividade de orientação profissional (OP) realizada em um cursinho pré-vestibular popular. Os objetivos foram sensibilizar para o processo de escolha do curso superior, favorecer a expressão de sentimentos com relação ao vestibular e ao próprio cursinho e promover a integração dos alunos. Fundamentando-se no psicodrama, a metodologia adotada envolveu debates grupais mediados pela produção de cartazes, a fim de favorecer a livre expressão de sentimentos mobilizados pelo vestibular e pela condição de freqüentadores do referido cursinho. Esses instrumentos permitiram também uma identificação e melhor integração entre os jovens, como também uma tomada de consciência de seus processos de escolha pelo curso universitário. Tal prática permitiu auxiliar esses alunos no reconhecimento das necessidades derivadas daquela condição, fortalecendo-os para o processo de escolha, para o enfrentamento da experiência do vestibular e também para a identificação e formação de vínculos com o grupo do qual faziam parte naquele momento.

Palavras-Chave: orientação profissional, escolha profissional, ansiedade, vestibular.

Abstract: The present article reports a vocational guidance (VG) activity carried out at a popular course for the university entrance examination (pré-vestibular). The objectives were to make the students aware of the choice of an undergraduation course, to potentialize the expression of feelings in relation to 'vestibular' and in relation to the course itself and to promote the integration among the students. The methodology used was based on psychodrama, which involved group debates mediated by the production of posts. The methodology aimed at potentializing the free expression of feelings that are hidden due to 'vestibular' and due to the behavioral condition of the students who attended the aforementioned course. The instruments used allowed better identification and integration among the students as well as the awareness of the process of choosing a university course. It was also possible to assist the students by the recognition of the needs derived from that behavioral condition making them ready to choose the university course and the 'vestibular' process, and also for their integration and identification with the group they belonged to at that moment.

Key words: vocational guidance (VG), vocational choice, anxiety, university entrance examination

\section{Situando a intervenção e seu contexto}

A prática da OP, independentemente de seu contexto, deve sustentar-se em uma compreensão teórico-conceitual a partir da qual suas ações serão desdobradas. Observando o contexto histórico-social contemporâneo, com os obstáculos enfrentados por jovens frente às demandas quando da inserção no mercado de trabalho, com as escolhas aí implicadas, constitui tarefa central da OP facilitar esse momento de escolha, cabendo ao profissional dessa área considerar a questão da conscientização de jovens e adultos a partir de sua sensibilização para o que ocorre efetivamente na sociedade em suas várias dimensões: econômica, política, social e educacional (Soares, 1987; 2002; Lisboa, 2000).

A diversidade de fazeres encontrada no mundo laboral faz com que a escolha de uma profissão ocupe uma dimensão cada vez mais central e complexa na vida dos sujeitos. Essa tarefa torna-se ainda mais difícil para o jovem 
trabalhador que provêm de uma condição socioeconômica desfavorável, haja vista que encontra objetivamente poucos espaços que lhe permitam o acesso à Universidade. Mesmo para essa clientela, no entanto, não se pode perder de vista que optar por uma profissão significa "definir o projeto de vida e o modo de conquistar a autonomia, o reconhecimento pessoal e a participação na sociedade através do trabalho” (Schiessl e Sarriera, 2004, p. 34), o que remete os jovens para aspectos mais amplos da sua vida, ligados à inserção profissional no mundo do trabalho em constante transformação.

Tradicionalmente, as intervenções de OP, voltadas para a tarefa de auxiliar na escolha do curso superior, atendem, sobretudo, uma clientela de classe média, que pode, de modo mais concreto, realizar essa escolha (Ribeiro, 2003). Soma-se a isso o fato de que, nos últimos anos, o acesso às universidades públicas brasileiras foi progressivamente tornando-se mais difícil devido ao aumento da concorrência candidato/vaga e não foi acompanhado por correspondente aumento no número de vagas. Nesse contexto desfavorável, vêm emergindo gradualmente outras formas de ingresso nas instituições de ensino superior, como o Exame Nacional do Ensino Médio (ENEM), o Sistema de Avaliação do Ensino Médio (SAEM) ou mesmo a seleção pelo currículo escolar do segundo grau. Entretanto, o processo seletivo ou exame vestibular ainda é predominante como mecanismo de seleção de estudantes para um curso de graduação, sobretudo nas universidades públicas, onde se verifica que a relação candidato/vaga é imensamente maior do que nas universidades particulares.

Etimologicamente, o termo vestibular referese a vestíbulo, átrio, entrada de um edifício (Ferreira, 1993). Na realidade brasileira, no entanto, muito mais do que porta de entrada, o vestibular acaba se tornando porta de saída, uma vez que a maioria dos candidatos não será classificada e não ingressará na universidade pretendida, vista a imensa desproporção candidato/vaga (Lucchiari, 1993; Bianchetti, 1996; Schiessl; Sarriera, 2004).

Nesse contexto de competitividade e exclusão, os cursinhos pré-vestibulares constituíram-se, nas últimas décadas, em uma possibilidade de incremento no preparo, visando à aprovação no concorrido exame. Esses cursinhos, segundo Bacchetto (2003), podem ser classificados em comerciais, quando atuam com fins lucrativos, e alternativos, ou populares, que se propõem a atender estudantes com baixo nível socioeconômico e podem ser gratuitos ou cobrar de seu alunado uma quantia simbólica.

De acordo com Soares (2002) e Bianchetti (1996), os cursos preparatórios privados possuem interesses puramente lucrativos e, dessa maneira, acabam por desvirtuar ainda mais os objetivos da educação brasileira, cujo enfoque deveria se assentar sob uma perspectiva de resolução efetiva das dificuldades cotidianas, pela adoção de mecanismos e métodos estratégicos para a solução de problemas com os quais as pessoas estão envolvidas em suas vidas diárias.

Os cursinhos são, na maioria, empresas especialistas na arte de fazer passar, atingindo uma grande população de classe média. Por se tratar de um acontecimento muito significativo na vida dos jovens, na dos seus familiares e também para a sociedade, as pessoas envolvidas em geral encontram-se suscetíveis a fazer investimento pelo "bem de meu filho” (Soares, 2002, p. 68).

Para os candidatos ao exame vestibular, nem sempre é possível preparar-se em um cursinho pré-vestibular, pois a maioria destes é de caráter privado e possui custo bastante elevado, com mensalidades por vezes superiores ao salário mínimo no Brasil. Frente a essas restrições, os cursinhos pré-vestibulares alternativos ou populares foram emergindo 
como iniciativas que visavam ao benefício da parcela da população sem condições de custear sua preparação ao ingresso na vida universitária.

Esses cursinhos, conforme assinala Bacchetto, iniciaram uma luta por políticas públicas de ação afirmativa que possibilitassem igualdade de acesso às universidades, em especial para estudantes da rede pública e afro-descendentes. O mesmo autor assinala também que "tais cursinhos apresentaram uma meta bastante ambiciosa, pois a desigualdade socioeconômica é patente em alguns cursos e carreiras e, historicamente, a maioria da população financeiramente desfavorecida nunca chegou próxima a esse nível de ensino” (Bacchetto, 2003, p. 16).

O cursinho onde ocorreu a intervenção aqui relatada é inserido em uma universidade federal, portanto, de iniciativa pública e sem a cobrança de mensalidades para a comunidade. Seu objetivo principal é proporcionar "o aumento da inclusão social de jovens carentes” (Miguez, 2004, p. 4). Para tanto, além de ministrar aulas sobre os conteúdos específicos focalizados no vestibular, também oferece serviços de assistência social, acompanhamento psicopedagógico e orientação profissional aos estudantes. Desde 2003, quando teve início, seus índices de aprovação em vestibulares de universidades federais, estaduais e particulares vêm subindo, igualando-se aos índices de cursinhos prévestibulares particulares nacionais, o que motiva e possibilita a continuação do programa (Miguez, 2004).

Em 2005, havia 400 alunos matriculados, na faixa etária de 18 a 48 anos (divididos em duas turmas extensivas, com 160 alunos, e três turmas semi-extensivas, com 240 alunos). O acesso às vagas desse cursinho se dá por meio de processo seletivo, do qual participam sujeitos que tenham sido contemplados com a isenção da taxa de inscrição no exame vestibular da mesma universidade, que residam nos arredores da cidade e que tenham concluído o ensino médio em escolas da rede pública. Neste ano, passaram a ser ofertadas vagas também para servidores da universidade e de fundações que prestam serviços à mesma e/ou seus dependentes, mediante outro processo de seleção, observados os mesmos critérios utilizados para os demais (D’avila, 2005; 2006).

A inserção do trabalho de OP nesse ambiente derivou de um convite dirigido pela coordenação do cursinho ao laboratório que presta serviços de informação e orientação profissional nessa universidade. A demanda apresentada era a de uma atividade capaz de prepará-los para o processo de escolha do curso universitário e, ao mesmo tempo, de promover a integração do corpo discente.

Preocupava a coordenação o fato de muitos alunos acabarem desistindo de freqüentá-lo por questões objetivas, como a necessidade de dupla jornada (trabalho durante o dia e cursinho pré-vestibular noturno), a distância entre o cursinho e a residência, os sucessivos deslocamentos, a falta de uma formação de base que os auxiliasse a acompanhar as matérias, enfim, todo um contexto excludente. Considerava-se, no entanto, que questões subjetivas poderiam estar igualmente implicadas nessas desistências, como a angústia e ansiedade em relação ao enfrentamento do vestibular, as reprovações anteriores e, principalmente, as dúvidas relacionadas à questão da escolha profissional. A respeito destas últimas, os estudantes questionavam junto à coordenação: "Será que vai valer a pena tanto sacrifício? Afinal, eu nem sei qual curso superior vou escolher!” (sic). Essas indagações retratam bem o entrelaçamento da ansiedade frente ao exame com a dificuldade de realizar a escolha pelo curso e, em conseqüência, a definição de um projeto de vida.

Enquanto prática destinada a intervir com jovens no momento em que concluem o 
A peculiaridade da situação vivida pelos vestibulandos remete-os a uma trajetória que envolve separação, perdas e ganhos nem sempre compensados pela aprovação no vestibular. ensino médio e se encontram em via de prestar o vestibular para ingressar em cursos universitários, a OP, no contexto brasileiro, tem se sustentado em contribuições teóricas de diversas abordagens, como mostram os estudos de Melo-Silva e Jacquemin (2001). Partindo de uma abordagem que privilegia o contexto social e compreende o desenvolvimento psicológico inserido nas interações e no contexto histórico-cultural, e dada a heterogeneidade das histórias de vida dos estudantes matriculados nesse cursinho, o trabalho aqui relatado ancorou-se principalmente em referenciais do psicodrama no que concerne aos procedimentos técnicos aplicados e à compreensão da dinâmica grupal emergente. Considerando os elementos fornecidos quando da solicitação, o trabalho foi desenvolvido por meio de técnicas artísticas e de dinâmica de grupo, tendo como objetivos sensibilizar para o processo de escolha do curso superior, favorecer a expressão de sentimentos com relação ao vestibular e ao próprio cursinho e promover a integração dos alunos.

\section{Algumas questões teóricas e metodológicas}

A atividade desenvolvida pautou-se na compreensão de que o homem é um ser histórico, portanto, constituído em seu movimento, ao longo do tempo, tanto pelas relações sociais como também pelas condições culturais engendradas. Nessa concepção histórico-cultural, o homem, em sua atuação sobre o mundo material, humaniza-se, apropria-se dos instrumentos produzidos pela humanidade e, ao mesmo tempo, transforma o mundo material. Em outras palavras, o homem objetivamente transforma o mundo e subjetivamente é também transformado enquanto atua.

A partir dessa concepção, a escolha está sempre presente, objetiva e subjetivamente, e faz parte das ações humanas. Então, o trabalho de OP pode realizar-se "em diferentes lugares, com diferentes objetivos, para diferentes populações, mas o que ele sempre deve ter em comum são os pressupostos teóricos básicos: o homem é sujeito de sua própria vida, é capaz de fazer escolhas mesmo em condições limitadas e, muitas vezes, determinantes" (Soares, 2000, p. 45). À luz desses pressupostos, considera-se de fundamental importância a contribuição da OP no ambiente de um cursinho pré-vestibular popular onde se impõe a precariedade da condição socioeconômica desses estudantes e, em conseqüência, o estreitamento de suas opções de futuro.

Dentre as diferentes temáticas trabalhadas em OP, a orientação ao vestibulando (Pimental; D'avila; Soares, 2005) se caracteriza por ser mais especializada, evidenciando a necessidade de abordar as várias dificuldades decorrentes da escolha profissional focada no curso superior, no qual a ansiedade diante do exame, as pressões sociais e familiares e o medo de ser reprovado são algumas das tônicas.

A peculiaridade da situação vivida pelos vestibulandos remete-os a uma trajetória que envolve separação, perdas e ganhos nem sempre compensados pela aprovação no vestibular.

“... ele se separa da sua escola, dos seus colegas e amigos e, muitíssimas vezes, até se afasta do lugar onde nasceu e da sua família. No período que antecede o vestibular, ele fica à margem de tudo e de todos os grupos; em termos escolares, não está mais na escola de $2^{\circ}$ grau, e a universidade continua cercada pelo fosso vestibular. (...) o vestibulando se encontra num lago revolto, com um pé numa canoa e outro noutra (...) O vestibular, como qualquer outro rito de passagem, traz um sentimento de perda muito grande: os colegas, os amigos, o lugar onde nasceu, a casa dos pais com tudo à mão, a necessidade de assumir 
autonomamente o seu processo vital, etc. Em relação aos ganhos, é algo que está muito difuso ainda. Está muito mais no campo das possibilidades. (Bianchetti, 1996, p. 43)”.

Já a escolha profissional, pela complexidade de fatores envolvidos, bem como pela angústia, medo e sofrimento que pode gerar a proximidade do vestibular, requer que o jovem seja assistido e apoiado pelos pais, educadores e orientadores profissionais. Essa escolha "não é algo que acontece de um instante para outro na vida das pessoas. Ela é parte de todo um processo de crescimento e reflexão pessoal bem como do conhecimento das profissões e de uma atividade profissional que se insere no social” (Soares, 2002, p. 92).

Conforme já assinalado, um processo de escolha deve considerar, no entanto, que a liberdade de escolha é restringida pelas condições socioeconômicas desfavoráveis dos sujeitos. Nas palavras de Schlichting, Soares e Bianchetti, “a possibilidade de escolha profissional está muito vinculada às condições objetivas com as quais o jovem se depara para efetivar sua opção por determinado curso ou carreira universitária” (2004, p. 121). Questões da ordem econômica e da produção material de sua existência são determinantes de possibilidades de escolhas de curso superior aos alunos; mesmo sabendo que gostariam de cursar Medicina ou Direito, por exemplo, a possibilidade de acesso e o custo financeiro desses cursos limitam suas escolhas.

Para fornecer o suporte psicológico necessário frente a essa demanda específica e no sentido de auxiliar na apropriação das escolhas, o trabalho com o conhecimento de si é fundamental, na medida em que possibilita ao sujeito conhecer suas características, interesses, aptidões, habilidades e respeitar o que está disposto a declarar e a compreender sobre si e sobre os outros naquele momento. Compreende-se que o autoconceito do jovem remete à construção da sua identidade, que também é um processo contínuo, fruto de seu sentimento de pertença a um determinado grupo social no qual estabelece suas relações. Portanto, a participação em grupos se constitui em um espaço de possibilidades de relações e de visões de si mesmo e de seu futuro profissional.

Do ponto de vista metodológico, na área da OP tem se privilegiado a abordagem grupal, não só pela possibilidade de acesso da intervenção a um número maior de pessoas mas também pela riqueza dessa modalidade de trabalho em proporcionar espaços de reflexão coletiva, já que todos se encontram frente à mesma demanda (Soares, 1987, Carvalho, 1995). Em contextos populares, especificamente, cresce a importância do recurso a essa abordagem, por possibilitar o acesso de um maior número de sujeitos ao atendimento em OP.

A abordagem grupal foi eleita como a mais adequada para o contexto apresentado. Essa modalidade inclui procedimentos de um trabalho de dinâmica de grupo, no qual o psicólogo deve estar preparado para o manejo do grupo nas mais diferentes situações (Soares; Krawulski, 1999 e 2002). Condições tais como os objetivos traçados, o espaço, a quantidade de sujeitos envolvidos, o tempo disponível para a realização da atividade e o número de monitores e coordenadores de grupo foram determinantes para que se decidisse a escolha pela abordagem grupal.

A técnica utilizada, escolhida após uma ampla discussão entre os coordenadores da atividade, considera sua relatividade, reconhecendo que essa escolha secunda a leitura do movimento grupal e dela deriva, na perspectiva apontada por Soares e Krawulski (2002). Nesse sentido, foi importante a busca de clareza em relação aos objetivos do encontro e à habilidade requerida para realizar eventuais modificações na condução do grupo para não perder sua dinâmica. 
Utilizou-se a técnica da colagem ou do cartaz (Soares, 1987, 2002; Soares, Krawulski, 1999). Essa técnica tem sido bastante utilizada por psicólogos no trabalho de grupo e consiste em fazer um objeto artístico colando sobre uma folha de papel fragmentos de diferentes materiais recortados (geralmente jornais, revistas e fotografias), em resposta a um tema proposto.

Focalizando o processo de escolha do curso superior, o vestibular, o cursinho e a integração entre o grupo de alunos, o enunciado proposto para a atividade buscou a construção de um discurso produzido pelos sujeitos a partir da colagem de figuras que representassem os seus sentimentos em relação a esses focos. Segundo Elizalde e Rodriguez (1990), a técnica tem dois momentos: o pré-verbal, quando o jovem observa as figuras e escolhe aquelas com as quais mais se identifica, e o momento verbal, quando o jovem explica a sua produção e, ao explicar, vai fazendo relações sobre a sua problemática. A confecção de cartazes coletivos dá oportunidade ao sujeito de refletir sobre a importância da escolha profissional, sobre o momento específico do vestibular e sobre o seu futuro. Ao falar sobre o momento vivido e a sua expectativa de futuro em relação ao vestibular, seu discurso representa uma explicação sobre seus projetos e sonhos, ao mesmo tempo em que expressa o momento que vivencia diante desses projetos.

Durante a confecção dos cartazes, observase um processo de identificação e um sentimento de "pertença”, favorecidos a partir da utilização dessa técnica, isto é, os jovens, ao perceberem que os colegas têm sentimentos parecidos com os seus, não se sentem mais tão sozinhos na fase que estão vivenciando, e passam a atualizar o seu autoconceito e a sua percepção em relação aos outros e ainda a resgatar a sua auto-estima. Os outros participantes também procuram atribuir significado às figuras, o que enriquece a reflexão. Ao participarem dos grupos, os sujeitos expressam, ao mesmo tempo, a partir de seus discursos, aquilo que é único e também coletivo em seus múltiplos significados.

\section{Desenvolvendo a atividade}

A experiência aqui relatada envolveu um grande grupo, com 127 alunos do cursinho, e foi coordenada por uma equipe composta por 2 professoras responsáveis, 1 doutoranda, 1 mestranda, estagiários do laboratório e alunos do curso de Psicologia matriculados na disciplina Seleção e Orientação Profissional II. O trabalho, com duração aproximada de três horas e meia, foi realizado em um corredor interno do prédio onde funciona o cursinho, por ser esse o local onde poderia ser alocado um maior número de pessoas. Os alunos haviam sido previamente convidados para participarem de uma atividade de integração, no horário em que normalmente teriam aulas, e foram orientados a levar revistas e tesoura. A descrição da atividade contemplará três momentos diferentes: o processo de aquecimento do grupo, a confecção dos cartazes e, por último, a socialização das produções grupais.

\section{O processo de aquecimento do grupo}

A intervenção foi iniciada com avisos a respeito do "contrato" sobre a atividade a ser desenvolvida e seus objetivos. Por meio de um microfone, foram apresentadas as coordenadoras e a equipe do laboratório, identificadas através de crachás, aos 127 alunos presentes. As professoras conduziram a atividade grupal, assumindo o papel de coordenadoras, enquanto os acadêmicos, por sua vez, atenderam aos subgrupos formados, desempenhando o papel de monitores e de observadores, e realizaram também registros escritos e fotográficos das atividades.

Buscando o aquecimento para a atividade, a coordenação propôs algumas consignas: 
caminhar como se estivesse chovendo, como se estivessem com muita pressa, como se estivessem cansados, como se estivessem muito tristes, para a direção oposta de onde estavam, seguindo outra pessoa como se fosse sua sombra, para perto das coordenadoras, aproximarem-se como se todos fossem entrar no mesmo elevador. A partir daí, foi se percebendo uma quebra da resistência inicial e progressiva mobilização e entusiasmo por parte dos estudantes quanto às orientações propostas.

Aquecidos para o trabalho a seguir e, uma vez que a maioria ainda não se conhecia, os estudantes foram orientados a dispersar-se, formando duplas com quem buscariam trocar informações como: nome, ocupação, bairro de residência, idade, curso pretendido no vestibular, entre outras. No momento seguinte, as duplas foram convidadas a formar quartetos e, finalmente, grupos de oito pessoas cada, o que configurou, desse modo, os subgrupos para compartilhar a execução da tarefa que seria proposta no segundo momento.

\section{O processo de confeccionar os cartazes}

Uma vez formados, os subgrupos receberam papel craft, revistas e material para recorte e colagem. Solicitou-se a realização de um cartaz que respondesse às seguintes perguntas: quais as expectativas com relação ao cursinho prévestibular popular da UFSC? E quais as expectativas com relação ao exame vestibular? Os cartazes, uma vez prontos, deveriam receber um título.

Como processo, esperava-se que essas questões favorecessem a emergência das principais expectativas dos jovens quanto à sua participação no cursinho e ao enfrentamento do vestibular. Esse foco na condição de freqüentadores do cursinho e na relação com o exame vestibular geraria, como produto, uma sensibilização para o processo de escolha profissional, uma vez que as escolhas desse público se encontravam, de algum modo, tramadas com o próprio cursinho enquanto oportunidade de preparação para o enfrentamento do vestibular e, em conseqüência, de ingresso na Universidade. Outro produto derivado de toda a atividade, porém melhor concretizado no momento de confeccionar o cartaz, seria a integração entre os alunos. A esse respeito, observou-se que alguns se envolviam na tarefa de maneira mais individual, outros coletivamente, socializando seus questionamentos com os demais e até mesmo oferecendo figuras ou frases relacionadas às suas áreas de interesse.

As coordenadoras do trabalho percorriam os subgrupos, acompanhavam a produção em curso e orientavam os monitores quanto a intervenções julgadas necessárias. Junto às gravuras, expressando o título ou não, os subgrupos colavam também palavras, expressões ou frases ilustrativas que traduziam suas preocupações, como o emprego e o desemprego e os sentimentos sobre o momento do vestibular.

A temática da escolha da profissão, juntamente à definição de um projeto de vida, esteve presente com maior ou menor intensidade em todos os subgrupos. No entanto, as discussões revelaram, em geral, a falta de informações sobre determinados cursos e profissões (Eu não conheço direito os cursos), a necessidade de ingresso no ensino superior, o medo da reprovação no vestibular ( $E$ tem o vestibular, também) e os sentimentos de dúvida e indecisão quanto ao futuro (O que eu quero no vestibular?).

Observou-se maior interesse manifesto por cursos menos concorridos, considerados menos tradicionais pela sociedade. A esse respeito, Levenfus (1997) explica que muitos alunos determinam suas escolhas com base apenas na facilidade de "passar", e dissociam 
"O medo da reprovação no vestibular pode alterar

significativamente o comportamento dos candidatos, sobretudo dos jovens que se preparam para a entrada no mundo adulto através desse exame".

Schiessl; Sarriera a aprovação no vestibular de sua finalidade, qual seja, estudar para futuramente exercer uma profissão. Essa questão, no entanto, se torna mais complexa ao se considerar que o jovem, ao pensar nas possibilidades de aprovação no vestibular ou de exercitar uma profissão, está projetando a sua vida em termos de futuro. A maneira como cada sujeito define o seu futuro profissional é muito singular, pois depende das experiências de sua vida pregressa: ante o ilimitado número de oportunidades que o mundo oferece na contemporaneidade, torna-se tarefa extremamente difícil projetar o caminho profissional; antecipá-lo é relacionar-se com a incerteza e com o seu campo de possibilidades, e pode gerar nos sujeitos medo e ansiedade (D’avila, 2006).

O medo da reprovação no vestibular pode alterar significativamente o comportamento dos candidatos, sobretudo dos jovens que se preparam para a entrada no mundo adulto através desse exame (Schiessl; Sarriera, 2004). Essas alterações podem envolver desde problemas de auto-estima, com a modificação da percepção que o jovem faz de si e da sociedade, até a depressão, déficit de atenção e estresse. Mais uma vez, o trabalho em OP aparece como fundamental para os vestibulandos.

Embora o temor à reprovação no vestibular tenha sido o aspecto menos mencionado pelos estudantes desses subgrupos, o trabalho de OP é fundamental para o resgate da autoestima dos reprovados e para auxiliar na sua “nova” escolha profissional. Ao referir-se a uma escolha universitária não compatível com suas expectativas, a estudante afirma: “Às vezes acontece alguma coisa para a gente ver que não era o caminho; a gente pega o errado pra depois achar o certo”. Em seu argumento, o fato de ter sido reprovada contribuiu para que pudesse realizar uma escolha mais realista.
Preocupações em conciliar o trabalho futuro com satisfação, felicidade e qualidade de vida também foram mencionada pelos sujeitos: “Tem que ser a foto de uma pessoa feliz?", perguntou um aluno no momento de escolher as figuras para compor o cartaz. "O que eu espero? Eu quero é viver bem”, explica outro, ao se expressar sobre o que pretende para seu futuro. Essas colocações corroboram as idéias de Bohoslavsky (1983) e Soares (2002; 2002a) no que se refere à busca da felicidade como elemento presente na escolha profissional, na tentativa de aliar a prática de um trabalho ao prazer.

Outro aspecto bastante discutido nos subgrupos refere-se à mudança de nível socioeconômico e à possibilidade de "progresso" na vida. Alguns estudantes afirmaram que essa ascensão é possível, mesmo se tiverem de enfrentar condições sociais e econômicas desfavoráveis. Para exemplificar tal afirmação, utilizaram a trajetória do Presidente Luis Inácio da Silva, colaram sua foto no cartaz e verbalizaram: "Se ele chegou lá... todos têm chance”. Tal debate mostra o quanto condições de ordem econômica, social e política repercutem nas escolhas dos sujeitos, e podem tanto facilitar um processo de mudança como de manutenção da condição presente.

Os alunos referiram-se também, com muita freqüência, à importância da educação em sua realidade. O depoimento "a educação primeiro, porque sem ela, né?” se assemelha ao que D’Avila afirmou em relação ao projeto profissional que inclui o ingresso no ensino superior. Nas palavras dessa autora, o projeto profissional de ingresso no ensino superior torna-se necessário para "ser alguém” no contexto atual da sociedade brasileira, uma vez que é pela via do trabalho, através da profissionalização, que poderá ocorrer mais facilmente essa inserção, e, dessa forma, os sujeitos passarem a acessar outros espaços da sociedade que, em momentos anteriores, permaneciam inacessíveis (2006, p. 85). 
Assim, para determinadas camadas da população, o acesso ao ensino superior acaba tornando-se uma estratégia para a concretização de outros projetos de vida, como, por exemplo, o projeto de mudar a condição social de origem, mesmo em uma sociedade marcada por transformações e crises socioeconômicas (Aued, 1999; Antunes, 2005), na qual o diploma de nível superior já não representa mais garantia de um emprego seguro e duradouro. Hoje, além do diploma universitário, é preciso atentar para outros valores incentivados pela lógica neoliberal vigente, tais como a autonomia ou a empregabilidade. Pensar no ingresso à Universidade remete à disputa por um lugar no concorrido mercado de trabalho, o que gera mais ansiedade e dúvidas nos vestibulandos, pois “será que vale a pena?”

A confecção dos cartazes permitiu que os participantes exprimissem em palavras alguns sentimentos mobilizados pela tarefa. Terminada a colagem, os subgrupos fizeram uma síntese sobre cada um dos elementos da sua produção, discutiram as expectativas em relação ao vestibular e ao cursinho e as formas como o cartaz podia ser entendido coletivamente. Os cartazes foram apresentados ao grande grupo, e foi escolhido um integrante para realizar essa tarefa. A partir desse momento, as discussões passaram a ser realizadas em um grande círculo, formado por todos os alunos, além dos demais participantes da atividade.

\section{O processo de socializar as produções grupais}

O momento de socialização das produções grupais, na realidade, "momento de apresentação” ao grande grupo, foi marcado por grande dispersão e alvoroço, salvo quando o grupo silenciava para ouvir aqueles que foram eleitos como seus representantes, o que, de certo modo, evidenciou a popularidade de alguns alunos.
Cada representante deveria apresentar a síntese da sua produção e a de seus colegas. Assim, à medida que falavam, buscavam a confirmação destes, o que propiciou maior mobilização do grupo e permitiu a participação de várias pessoas, que expressaram seus sentimentos. A produção que mais se destacou no grande grupo trazia a importância do lazer e dos momentos de descontração para alívio da ansiedade. Esse cartaz apresentava frases tais como Sem Estresse e A vida no Topo (associada à imagem de um atleta no pódio). Foi solicitado que apontassem semelhanças e diferenças entre os cartazes, e, nesse momento, emergiram diversas questões, que foram discutidas em conjunto e que puderam ser agrupadas em três temáticas. A primeira delas buscava compreender como o vestibulando poderia conciliar o estudo e/ou o trabalho com as relações familiares, de amizade e namoro. Num primeiro momento, as mudanças na vida do jovem decorrentes da necessidade de preparação para o vestibular podem implicar inúmeras perdas (a insuficiência de vagas, a concorrência acirrada, a escolha por apenas um curso universitário, dentre vários disponíveis, a jornada de estudos, a diminuição do tempo de lazer, dentre outros), ao passo que seus ganhos são projetados em um futuro e ainda se configuram como possibilidades (a aprovação no vestibular, a inserção no mercado de trabalho, um futuro melhor). Dessa forma, uma série de exigências e responsabilidades se transpõe para a vida do jovem, o que o leva a perceber, aos poucos, que o que está em jogo é o seu próprio destino profissional. Para aqueles que já se encontram inseridos no mercado de trabalho, a rotina de estudos se torna ainda mais complicada, pois, além das atividades laborais, acrescenta-se o que é estudado no cursinho. Nesse sentido, outros aspectos da vida, como relacionamentos e lazer, acabam ficando em segundo plano. Frases do tipo: vamos colocar um relatório e dizer que a gente não tem mais tempo pra nada ilustram bem essa dificuldade. 
Uma segunda temática ressaltada referia-se às diferentes trajetórias de vida e visões de mundo compartilhadas entre os estudantes do cursinho. O alunado, composto por adultos, jovens e adolescentes, concluiu que essa heterogeneidade poderia auxiliar no enfrentamento do vestibular, dada a riqueza de histórias de vida. Os trabalhos de D’Avila (2006) e de Bonfim (2003), desenvolvidos com a clientela de cursinhos pré-vestibular, verificaram a existência de um convívio harmonioso, amistoso e cooperativo entre o alunado. Esses elementos, também observados no decorrer dessa atividade, confirmam o alcance de um dos objetivos traçados, qual seja, a integração do grupo.

Como última temática, foi ressaltada a importância de se realizar uma escolha profissional preocupada com o compromisso social, de forma que a profissão venha a ser um meio de promover mudanças sociais. Nesse sentido, alguns cartazes foram intitulados Mais Saúde Para Todos e Todos por um.

Não obstante alguma dispersão e barulho quando da socialização das produções dos subgrupos, verificou-se que foi um momento muito rico, no qual houve grande compartilhamento de sentimentos em relação ao vestibular, ao cursinho, às escolhas em curso ou já feitas e ao sentimento de pertença ao grupo que começava a se desenvolver.

\section{Discutindo a atividade e tecendo algumas considerações}

Oriunda de uma tradição de intervenção relacionada à escolha do curso superior junto a contextos socio-econômicos de classe média, como já se afirmou, a prática da OP, transposta para um contexto coletivo como o ambiente do cursinho popular, evidenciou o quanto questões da ordem socioeconômica são determinantes e dificultam não apenas o processo de escolha mas também as possibilidades de acesso ao ensino superior. Nesse sentido é que se podem explicar as escolhas desse público, que se volta, via de regra, para cursos de menor concorrência no vestibular como estratégia de viabilizar esse acesso.

Não obstante essa diferença, é inegável a necessidade, também nesses contextos, de sensibilizar os alunos para a importância de um processo de escolha do curso superior, pois esses jovens se sentem do mesmo modo indecisos e "perdidos", o que revela um campo de atuação para a inserção do trabalho de OP. A indecisão relativa à escolha foi um dos temas importantes que emergiu na atividade e apontou o quanto essa questão representava uma necessidade daquele coletivo. Esse dado, analisado mais detidamente em momento posterior, confirmou a importância de um trabalho de acompanhamento de OP mais sistematizado ao longo do ano, que foi realizado pela orientadora profissional contratada pelo cursinho a partir dos subsídios decorrentes da intervenção aqui relatada.

Essa atividade, embora limitada em tempo e alcance, pautou-se na idéia de que a OP “deve trabalhar para o bem-estar psicossocial do indivíduo, sendo, assim, um trabalho de saúde mental. E, se possível, deve ser um trabalho que busque resgatar a felicidade, para que a pessoa possa ser feliz no desempenho de seu trabalho" (Soares, 2000, p. 45, grifos da autora). Tal idéia ganha maior importância ao se considerar o contexto em que foi desenvolvida, uma vez que, em todo o País, os cursinhos populares representam políticas públicas de ação afirmativa ao buscar minimizar as desigualdades no acesso ao ensino superior. Esses espaços têm apresentado resultados positivos no aumento da inserção de populações carentes nas universidades. Esse cursinho pré-vestibular popular, especificamente, por estar vinculado formalmente a uma universidade pública e 
gratuita, tem possibilitado aos seus alunos se considerarem pertencentes ou detentores do direito de acesso ao ensino superior, haja vista que já usufruem condições semelhantes aos alunos dos cursos de graduação, como a utilização da biblioteca, do restaurante universitário e dos laboratórios de informática, o que lhes garante acesso à internet. Além desse aspecto, os alunos consideram uma conquista sua seleção dentre os quase três mil candidatos isentos concorrentes às vagas nesse espaço. Assim, mesmo que não passem no vestibular num primeiro momento, conseguem visualizar tal possibilidade no futuro, o que resulta num processo de diminuição da ansiedade no que se refere ao vestibular e ao resgate de sua auto-estima. Esses aspectos explicam os sentimentos positivos predominantemente expressos nos cartazes quanto à condição de alunos do cursinho.

A menor ansiedade frente ao exame vestibular constatada nesse público não coincide com o resultado de outras pesquisas desenvolvidas com vestibulandos (D'AVILA; SOARES, 2003). Pode-se conjecturar que o fato de ainda faltarem vários meses para o vestibular quando a atividade foi realizada tenha contribuído para essa postura mais tranqüila. No entanto, os estudantes expressaram em suas produções a importância de desenvolver estratégias para alívio de sua ansiedade ainda presente, através de atividades de lazer e descontração.

Considera-se que os objetivos traçados para a atividade foram alcançados, pois foi possível sensibilizar os alunos para a escolha do curso superior através da manifestação de sentimentos com relação ao cursinho, ao vestibular e das motivações, interesses e valores grupais, conforme verbalizado ao final das atividades. A questão da integração, que fora uma das solicitações originais, também foi atendida, pela oportunidade de os participantes se conhecerem um pouco mais e poderem, a partir daí, realizar atividades extraclasse ou mesmo se encontrarem fora do ambiente do cursinho, conforme foi explicitado. A prática da OP, desse modo, pretendeu ter contribuído para dar voz aos atores sociais e suprir parte das necessidades explicitadas pelos próprios sujeitos envolvidos no processo.

Para os coordenadores, evidenciou-se a necessidade de sintonia nos papéis entre estes e os monitores e observadores, como forma de complementaridade na condução do grupo. Era preciso coordenar não apenas o trabalho junto à clientela, mas também o grupo de monitores, alguns inseguros e sem iniciativa quanto ao que fazer.

Cabe registrar o quanto foi proveitoso o encontro, ainda que breve, com jovens e adultos que, mesmo imersos nesse turbilhão de indecisões e necessidade de construção de suas próprias vidas, não se esqueceram de sonhar e de se sentirem responsáveis diretos pela luta por um mundo melhor, para si próprios e para a coletividade onde estão inseridos.

Ressalta-se também que essa intervenção mostrou o quanto as práticas de OP e de orientação ao vestibulando são interdependentes e precisam ser trabalhadas juntas, em alguma medida, uma vez que o jovem se confronta não apenas com o desafio de escolher mas também com a necessidade de desenvolver estratégias que lhe permitam melhor enfrentar o vestibular. Podemos afirmar que ocorre, de fato, um entrelaçamento do processo de escolha com os sentimentos provocados pela aproximação do exame. A esse respeito, Soares, em seus relatos de trabalhos com grupos de orientação ao vestibulando, afirma existir uma diferença entre os participantes de grupos que haviam feito parte, anteriormente, de OP e os que não haviam. Em suas palavras, "os primeiros estavam muito mais motivados para o estudo, pois tinham mais certeza da sua escolha e, 
por isso, depositavam toda energia em busca da classificação no vestibular, enquanto os segundos não conseguiam estudar por estarem muito mais preocupados em verificar se tinham feito a melhor escolha” (2002, p. 338). Além desse aspecto, a atividade realizada, ao possibilitar aos participantes identificarem-se com os colegas e perceberem que não estavam sozinhos, pois os colegas de cursinho vivenciavam sentimentos semelhantes aos seus, evidenciou a legitimidade da modalidade grupal como proposta de trabalho no contexto coletivo aqui caracterizado, ao estender o alcance da OP a camadas que, de outro modo, não teriam acesso a essa prática. A atividade, pelo fato de privilegiar o coletivo, trouxe à tona diversos temas e conteúdos que envolvem o mundo do vestibulando, onde as ansiedades e incertezas constituem a grande preocupação.

Dulce Helena Penna Soares

Psicóloga, Doutora em Psicologia Clínica. Docente do Curso de Graduação e do Programa de Pós Graduação em Psicologia da Universidade Federal de Santa Catarina (UFSC).

Edite Krawulski

Psicóloga, Mestre em Administração e Doutora em Engenharia de Produção - área de Ergonomia.

Docente do Curso de Graduação e do Programa de Pós - Graduação do Departamento de

Psicologia da UFSC.

Maria Sara de Lima Dias

Universidade Federal de Santa Catarina - psicóloga, Mestre em Psicologia Social e doutoranda do Programa de Pós-Graduação em Psicologia da UFSC.

\section{Geruza T. D’Avila}

Psicóloga e Mestre em Psicologia pelo Programa de Pós-Graduação da UFSC.

Dulce Helena Penna Soares. Laboratório de Informação e Orientação Profissional www.liop.ufsc.br. Departamento de Psicologia. Centro de Filosofia e Ciências Humanas. Campus Universitário Trindade. Florianópolis - SC. Caixa Postal: 476 - CEP 88010-970. Fax: (48) 37219984. Telefones (48) 37218213 e (48) 37219402. E-mail: dulcepenna@terra.com.br 
ANTUNES, R. O caracol e sua concha: ensaios sobre a nova morfologia do trabalho. São Paulo: Boitempo, 2005.

AUED, B. W. Introdução. In: AUED, B. W. (Org.). Educação para o (des)emprego. Petrópolis: Vozes, 1999.

BACCHETTO, J. G. Cursinhos pré-vestibulares alternativos no Município de São Paulo (1991-2000): a luta pela igualdade no acesso ao ensino superior. Dissertação (mestrado em Educação) Programa de Pós-Graduação em Educação da Universidade de São Paulo, São Paulo, 2003.

BIANCHETTI, L. Angústia no vestibular: indicações para pais e professores. Passo Fundo: Ediupf, 1996.

BOHOSLAVSKY, R. Vocação e alienação profissional. In BOHOSLAVSKY, R. (Org.). Teoria, técnica e ideologia. São Paulo: Cortez, 1983.

BONFIM, T. A. O CAPE em nossas vidas: a visão de um grupo de alunos, ex-alunos e colaboradores sobre um curso pré-vestibular gratuito. Dissertação (mestrado em Educação) - Programa de PósGraduação em Psicologia e Educação/FFCLRP. Universidade de São Paulo, Ribeirão Preto, 2003.

CARVALHO, M. M. Orientação profissional em grupo. Campinas: Psy, 1995.

D’AVILA, G. T. Projeto profissional de vestibulandos: um estudo de caso no cursinho pré-vestibular popular da Universidade Federal de Santa Catarina. Projeto de dissertação aprovado em exame de qualificação como requisito parcial à obtenção do título de Mestre. Programa de Pós-Graduação em Psicologia da Universidade Federal de Santa Catarina, Florianópolis, 2005

O ensino superior como projeto profissional para "ser alguém": repercussões de um cursinho pré-vestibular popular na vida dos estudantes. Dissertação (mestrado em Psicologia) - Programa de Pós-Graduação em Psicologia da Universidade Federal de Santa Catarina, Florianópolis, 2006.

D’AVILA, G. T.; SOARES, D. H. P. Vestibular: fatores geradores de ansiedade na cena da prova. Revista Brasileira de Orientação Profissional. Porto Alegre, v. 1/2, n. 4, p. 105-116, 2003.

ELIZALDE, J.; RODRIGUEZ, A. Orientación vocacional: espacio de reflexión, confrontación y creación. Montevidéo: Editorial Roca Viva, 1990

FERREIRA, A. B. de H. Novo Dicionário da Língua Portuguesa. $2^{a}$ ed. Rio de Janeiro: Nova Fronteira, 1993.

LEVENFUS, R. S. Faça o vestibular com seu filho, faça o vestibular com seus pais. Porto Alegre: Artes Médicas, 1997.

LISBOA, M. D. A formação de orientadores profissionais: um compromisso social multiplicador. In: LISBOA, M. D; SOARES, D. H.P. (Orgs.) Orientação profissional em ação: formação e prática de orientadores. São Paulo: Summus, 2000. cap. 1.

LUCCHIARI, D. H. P. S. A questão do vestibular. In: LUCCHIARI, D. H P. S. (Org.) Pensando e vivendo a orientação profissional. São Paulo: Summus, 1993. cap. 14
MELO-SILVA, L.; JACQUEMIN, A. Intervenção em orientação vocacional/profissional: avaliando resultados e processos. $1^{\mathrm{a}} \mathrm{ed}$. São Paulo: Vetor Psico-Pedagógica, 2001. v. 1.

MIGUEZ, M. J. B. Cursinho da UFSC - Inclusão para a vida Programa de Apoio à Extensão Universitária voltado para as Políticas Públicas - PROEXT 2004 - SESu/MEC. Florianópolis, 2004.

MONTEIRO, R.F. Jogos dramáticos. São Paulo: McGraw-Hill do Brasil, 1979.

PIMENTEL, R. G.; D’AVILA, G. T.; SOARES, D. H. P. Grupos de orientação ao vestibulando: relato de alguns instrumentos utilizados na OV presencial e via Internet. In: MAHL, A. C.; SOARES, D. H. P.; NETO, E. de O. (Orgs.). Programa de orientação profissional intensivo: outra forma de fazer orientação profissional. São Paulo: Vetor, 2005.

RIBEIRO, M. A. Demandas em orientação profissional: um estudo exploratório em escolas públicas. Revista Brasileira de Orientação Profissional. v. 1/2, n. 4, p. 141-151, 2003.

SCHIESSL, C. S.; SARRIERA, J. C. Refletindo a questão do ingresso ao ensino superior: dificuldades e expectativas dos jovens de ensino médio. In: SARRIERA, J. C.; ROCHA, K. B.; PIZZINATO, A. (Orgs.). Desafios do mundo do trabalho: orientação, inserção e mudanças. Porto Alegre: EDIPUCRS, 2004.

SCHLICHTING, A. M. S.; SOARES, D. H. P. e BIANCHETTI, L. Vestibular seriado: análise de uma experiência em Santa Catarina. Psicologia \& Sociedade. v. 16, n. 2, p. 114-126, 2004.

SOARES, D. H. P. O jovem e a escolha profissional. Porto Alegre: Editora Mercado Aberto, 1987.

As diferentes abordagens em orientação profissional. In: LISBOA, M. D; SOARES, D. H. P. (Orgs.) Orientação profissiona em ação: formação e prática de orientadores. São Paulo: Summus, 2000. cap. 2.

Como trabalhar a ansiedade e o estresse frente ao vestibular In:LEVENFUS, R. S.;SOARES, D.H. P.(Orgs.). Orientação vocacional ocupacional: novos achados teóricos, técnicos e instrumentais para a clínica, a escola e a empresa. Porto Alegre: Artmed, 2002. cap. 23.

A escolha profissional: do jovem ao adulto. São Paulo: Summus, 2002a.

SOARES, D. H. P.; KRAWULSKI, E. Modalidades de trabalho e utilização de técnicas em orientação profissional. In: LEVENFUS, R. S.; SOARES, D. H. P. (Orgs.). Orientação vocacional ocupacional: novos achados teóricos, técnicos e instrumentais para a clínica, a escola e a empresa. Porto Alegre: Artmed, 2002. cap. 20.

SOARES, D. H. P.; KRAWULSKI, E. O desenvolvimento de novas técnicas em orientação profissional no LIOP - Laboratório de Informação e Orientação Profissional. In: LASSANCE, M. C. (Org.) Técnicas para o trabalho de orientação profissional em grupos. Porto Alegre: Editora da UFRGS, 1999. p. 59-86.

\section{Referências}

